\title{
Antidepressant-like effects of physical activity versus imipramine: Neonatal clomipramine model
}

\author{
H. S. YOO, R. L. TACKETT, J. B. CRABBE, B. N. BUNNELL, and R. K. DISHMAN \\ University of Georgia, Athens, Georgia
}

\begin{abstract}
The clomipramine (CLI) model of depression was used to examine whether exercise has antidepressant-like effects. Male Sprague-Dawley pups were injected with CLI-HCl $(40 \mathrm{mg} / \mathrm{kg} / \mathrm{day})$ from age 8 to 21 days. At age 4 weeks, rats were assigned to one of five conditions: (1) sedentary; (2) 24-h access to an activity wheel; (3) sedentary + imipramine-HCl $(10 \mathrm{mg} / \mathrm{kg} /$ twice daily) during the last 10 days of the experiment; (4) wheel running + imipramine; (5) daily treadmill running. At age 16 weeks, rats underwent sex behavior testing. The rate of copulation was lower in the sedentary CLI-treated group than in the saline controls. Reductions in measures of sexual arousal and levels of monoamines were consistent with the CLI model of depression but were smaller than expected. Wheel runners had more frequent mounts, intromissions, and ejaculations relative to the other groups. Norepinephrine levels in brain frontal cortex were higher in all running groups and the imipramine group relative to the sedentary CLI and saline groups. Radioligand [ $\left.{ }^{125} \mathrm{I}\right]$ binding density $\left(\mathrm{B}_{\mathrm{Max}}\right)$ of $\beta$-adrenoceptors in frontal cortex was lower for the wheel running, imipramine, and wheel running + imipramine groups. Activity wheel running equaled imipramine treatment for increasing norepinephrine and decreasing $B_{\text {Max }}$, and it exceeded imipramine treatment for increasing male copulatory performance. We conclude that activity wheel running favorably influences several hallmark pharmaco-physiological and behavioral measures of an antidepressant effect but did not alter sexual arousal, a surrogate measure of anhedonia. The weaker than expected effects of CLI treatment indicate that the generalizability of the CLI model requires further elucidation using convergent behavioral, biochemical, and pharmacological measures.
\end{abstract}

About 100 clinical and analog studies have reported that exercise reduces symptoms of depression by about 0.5 SD (McDonald \& Hodgdon, 1991; North, McCullagh, \& Vu Tran, 1990; Simons, Epstein, McGowan, Kupfer, \& Robertson, 1985). However, the scientific and clinical quality of that evidence has been judged weak (Harris, Caspersen, DeFriese, \& Estes, 1989; Morgan, 1994). Notably, the absence of evidence for plausible mechanisms that could explain an antidepressant effect of exercise (Dunn \& Dishman, 1991) has limited the acceptance of physical activity for the purposes of primary or secondary prevention of depression (American Psychiatric Association, 1993).

Ransford (1982) proposed that chronic exercise may exert an antidepressant effect by normalizing or enhancing brain monoamine systems in a manner similar to the effects of chronic administration of antidepressant drugs (Baldessarini, 1989). Studies of chronic exercise have reported effect sizes of about $0.5 S D$ for levels of norepinephrine (NE), 3-methoxy-4-hydroxy-phenylglycol (MHPG), and 5-hydroxyindole acetic acid (5-HIAA) and $0.25 S D$

Thanks go to Gerald W. Vogel for his advice regarding the clomipramine treatment. Current address for Ho Sang Yoo: Yeungnam University, Gyongsan, Gyongbuk, South Korea. Correspondence should be addressed to R. K. Dishman, Department of Exercise Science, The University of Georgia, Ramsey Student Center, 300 River Road, Athens, GA 30602-6554 (e-mail: rdishman@coe.uga.edu). for 5-hydroxytryptamine (5-HT) in rat brain (Blomstrand, Perrett, Parry-Billings, \& Newsholme, 1989; Broocks, Liu, \& Pirke, 1990; Brown et al., 1979; Brown \& Van Huss, 1973; Chaouloff et al., 1987; deCastro \& Duncan, 1985; Dey, Singh, \& Dey, 1992; Dunn, Reigle, Youngstedt, Armstrong, \& Dishman, 1996; Elam, Svensson, \& Thoren, 1987; Hellhammer, Hingtgen, Wade, Shea, \& Aprison, 1983; Ostman \& Nyback, 1976; Rea \& Hellhammer, 1984). Most of those studies confounded the exertion of exercise with other stressors, but there is evidence that treadmill exercise training and activity wheel running increase brain NE (Brown et al., 1979; Dunn et al., 1996) and 5-HT (Dishman et al., 1997) independently of other stressors. Though limited to postmortem estimates, those studies, and a report of blunted NE depletion in locus coeruleus after repeated footshock among activity wheel runners (Dishman et al., 1997), have led to the hypothesis that physical activity leads to healthful adaptations in the brain NE response to stress among physically active rats (Sothmann et al., 1996).

Using the footshock escape model of depression (Weiss et al., 1981), we recently reported experimental evidence consistent with an antidepressant effect of exercise (Dishman et al., 1997). In that study, rats with 24-h access to running wheels for 6 weeks had shorter escape latency than sedentary control animals after exposure to inescapable shock. The sedentary rats had lower NE in locus coeruleus and higher 5-HT and 5-HIAA levels in 
hippocampus and central amygdala. In a follow-up study using microdialysis, we found that wheel runners had a blunted release of NE in the frontal cortex in response to footshock, despite no change in mRNA for tyrosine hydroxylase in the locus coeruleus (Soares et al., 1999).

One hypothesis that has emerged from those studies is that chronic physical activity may normalize the locus coeruleus-norepinephrine system in ways similar to the effects of chronic antidepressant drugs (Baldessarini, 1989), but the methods used heretofore have been limited to the inescapable shock model of depression, which may model neurotic precursors to depression (Drugan, Ryan, Minor, \& Maier, 1984; Gray, 1985). Vogel, Neill, Hagler, and Kors (1990) have advanced an animal model that appears to mimic endogenous depression. Administration of the monoamine reuptake inhibitor clomipramine (CLI) to neonatal rats manifests signs that mimic several features of human endogenous depression when the rats reach 3 7 months of age. The model has been validated by behavioral signs associated with depression (i.e., male copulatory behavior, REM sleep abnormalities, forced-swim immobility, and decreased intracranial self-stimulation; BonillaJaime, Retana-Marquez, \& Velazquez-Moctezuma, 1998; Mirmaran, Van de Poll, Corner, Van Oyen, \& Boer, 1981; Velazquez-Moctezuma \& Ruiz, 1992; Vogel, Neill, Hagler, Kors, \& Hartley, 1990; Vogel, Neill, Kors, \& Hagler, 1990), by reversal of depressive signs with antidepressant imipramine treatment (Vogel, Neill, Hagler, \& Kors, 1990), and by a decrease in neural discharge in the dorsal raphe nucleus (Kinney, Vogel, \& Feng, 1997; Yavari, Vogel, \& Neill, 1993). The model is generally isomorphic with human depression, and it is responsive to pharmacotherapy. Since its endogenous etiology differs from other animal models based on exogenous stress, the CLI model has potential for studying the role of physical activity in preventing depression not arising from chronic stress. However, the validity of the CLI model has not been established using measures of brain monoamines and receptor changes assessed concomitantly with a behavioral sign of depression.

The purpose of the study we report herein was to determine whether chronic voluntary wheel running or forced treadmill running protects against a behavioral sign of major depression and is accompanied by adaptive changes in brain noradrenergic and serotonergic systems, similar to the effects of the antidepressant drug imipramine. Depression was experimentally modeled in neonatal male rats by chronic injections of CLI using the model of Vogel, Neill, Hagler, and Kors (1990). We used male copulatory behavior to mimic the anhedonia characteristic of major depression (Koob, 1989). An additional test of the validity of the CLI-induced animal model was provided by assays of brain NE and 5-HT and their metabolites, as well as the binding density and affinity of $\beta$-adrenergic receptors, in the brain frontal cortex. Chronic administration of imipramine in combination with acute swim stress has been shown to elicit greater reductions in $\beta$-adrenoceptor number relative to chronic imipramine treatment alone (Duncan et al., 1985). However, it is not known whether physical activity has an effect that is independent or additive with pharmacotherapy in the treatment of depression (Martinsen \& Stanghelle, 1997).

The frontal cortex was chosen because it is densely innervated with NE and 5-HT efferents (Cenci, Kalen, Mandel, \& Bjorkland, 1992; Foote, Bloom, \& AstonJones, 1983; Holets, 1990), which modulate behavioral and physiological responses during stress (Glavin, 1985; Heinsbroek, van Haaren, Feenstra, Boon, \& van Poll, 1991), including those associated with depression (Weiss et al., 1981). It also shows a down regulation of $\beta$-adrenoreceptors after repeated stress (Stanford, 1990) and antidepressant drug treatment (Baldessarini, 1989).

We report that circadian wheel running, but not forced treadmill running, equaled imipramine treatment in increasing brain cortical levels of NE and decreasing $\beta$ adrenoceptor density, and it exceeded imipramine treatment for increasing male copulatory performance. Our results indicate that voluntary physical activity has antidepressant-like effects.

\section{METHOD}

\section{Subjects}

Pregnant female Sprague-Dawley derived rats $(N=24)$ obtained from the Charles River Laboratory (Raleigh, NC) delivered their pups 1 week after arrival at our vivarium. Three days postnatally, all male pups were cross-fostered. Thirty-six female pups were saved as partners for sexual activity testing. Sixty males were treated intraperitoneally with $\mathrm{CLI}-\mathrm{HCl}(40 \mathrm{mg} / \mathrm{kg})$ once daily, at $1700 \mathrm{~h}$ on postnatal Days 8-21 (Vogel, Hagler, Hennessey, \& Richard, 1996). A control group of 12 pups received a saline vehicle treatment. At 4 weeks of age, all pups were weaned and individually housed in shoebox cages with activity wheel cages or shoebox cages without activity wheels. The home cage was $20 \times 18 \times 24 \mathrm{~cm}$ in size. The rooms in which all rats were housed were maintained at $23^{\circ} \pm 1^{\circ} \mathrm{C}$. All animals were kept on a reversed 12:12-h light:dark cycle (light $2400-1200 \mathrm{~h}$ ). Rat chow and water were available ad lib.

\section{Research Design}

The CLI pups ( $N=60$ ) were randomly assigned to five groups: (1) sedentary home cage control; (2) voluntary activity wheel running; (3) antidepressant imipramine treatment; (4) activity wheel running + imipramine treatment; and (5) treadmill training. Group 6 was a saline vehicle control that was sedentary. Nine fatalities from an unexplained bacterial infection occurred within the 1 st month of the experiment and were balanced across conditions. Three rats assigned to the treadmill condition stopped running before the end of the study and were excluded from analysis. The dependent measures included the following: (1) male copulatory behavior (mount latency, mount frequency, intromission latency, intromission frequency, ejaculation frequency, and postejaculatory interval); (2) levels of NE, 5-HT, MHPG, and 5-HIAA in a hemisphere of the frontal cortex selected in a counterbalanced manner across conditions; and ( 3 ) density and affinity of $\beta$-adrenoceptors in the other hemisphere.

\section{Experimental Treatments}

Activity wheel running. Rats assigned to the activity wheel and the activity wheel + imipramine groups were individually housed in 
cages with 24-h access to running wheels (MiniMitter, Sunriver, OR) for 12 weeks. The circumference of the wheel was $105 \mathrm{~cm}$. Daily running distance was determined by multiplying the wheel circumference by the number of wheel revolutions indicated by an electromagnetic counter.

Treadmill training. Rats assigned to the treadmill training group were familiarized with a Stanhope (Davis, CA) motor-driven treadmill during a 3-day period. The rats ran for $5 \mathrm{~min}$ at $5 \mathrm{~m} / \mathrm{min}$ and $0^{\circ}$ incline and then were gradually adapted to treadmill running for 2 weeks. The exercise duration was increased from 15 to $30 \mathrm{~min}$ and the speed was increased from 15 to $25 \mathrm{~m} / \mathrm{min}$ during the $1 \mathrm{st}$ week. By the end of 2 nd week animals ran for $60 \mathrm{~min}$ at $30 \mathrm{~m} / \mathrm{min}$. This regimen was maintained 6 days per week for an additional 10 weeks. Electric shock was never used to motivate running performance. Treadmill training was conducted in a dim red light environment during the dark phase of 12:12-h light:dark cycle to minimize circadian rhythm and sleep disturbance effects and to permit direct comparisons with activity wheel running that occurs predominantly during the dark phase. This protocol corresponds to a moderate exercise intensity of $50 \%-60 \%$ of $\mathrm{VO}_{2 \text { peak }}$ for SpragueDawley males (Armstrong, Laughlin, Rome, \& Taylor, 1983).

Imipramine injection. Twelve days prior to sexual activity testing, rats assigned to the imipramine and the wheel running + imipramine groups were injected intraperitoneally with imipramine $\mathrm{HCl}(10 \mathrm{mg} / \mathrm{kg})$ twice daily $(800$ and $1800 \mathrm{~h}$ ) for 10 days (Duncan, Paul, \& Breese, 1993). An equivalent volume of saline was injected into all other groups.

\section{Sexual Activity Testing}

At 16 weeks of age ( $48 \mathrm{~h}$ after the last imipramine injection or the last exercise session), animals underwent sexual activity testing. Each female's receptivity was induced by intramuscular injection of $50 \mu \mathrm{g}$ of estradiol $72 \mathrm{~h}$ prior to testing and $0.5 \mathrm{mg}$ of progesterone $3-6 \mathrm{~h}$ before testing. The injected females were pretested with nonexperimental male rats just before testing, and nonreceptive females were excluded. The testing took place between $1300 \mathrm{~h}$ and $2000 \mathrm{~h}$ during the dark phase of the 12:12-h light:dark cycle. Each male rat had a 5 -min adaptation period in the testing chamber before a female was introduced.

The sexual activity testing chamber was a circular Plexiglas arena $34 \mathrm{~cm}$ high and $91 \mathrm{~cm}$ in diameter located in a thermoneutral testing room dimly illuminated $(\sim 2 \mathrm{Ix})$ by a red light. The test session for each male rat lasted $30 \mathrm{~min}$ after the first complete intromission. The test session lasted $20 \mathrm{~min}$ for those rats that showed no copulatory behavior. Each female partner was paired with only 1 male. Paper bedding on the chamber floor was changed after each male was tested

Sexual behavior was recorded by two observers who were blind as to the rats' experimental group classification. The following standard measures of male copulatory behavior were obtained from the observations according to the definitions of Dewsbury (1967): mount latency (ML), the time between the introduction of a female and the first posterior mount by the male; mount frequency (MF), the cumulative number of posterior mounts; intromission latency (IL), the time between introduction of the female and the first complete vaginal penetration by the male (when the first mount by a male results in an intromission, ML and IL are the same); intromission frequency (IF); ejaculation frequency (EF), the cumulative number of ejaculations; and postejaculatory interval (PEI), the time between an ejaculation and the first intromission when the male resumes copulating in the next ejaculatory series. Owing to the low $\mathrm{EF}$ in most groups, PEI was compared only for the first series. ML and $\mathrm{IL}$ are generally assumed to reflect sexual arousal or motivation, and MF, IF, and EF are used as indicators of copulatory performance. The PEI reflects the recovery time needed before initiating the next bout of copulatory activity and is regarded as another measure of motivation. When a PEI extended beyond the 30 -min dura- tion of the test session, the test was continued until it was terminated by an intromission or until $20 \mathrm{~min}$ had elapsed.

\section{NE, 5-HT, 5-HIAA, and MHPG Assays}

Twenty-four hours after sexual activity testing, rats were killed by guillotine decapitation. The frontal cortex was rapidly excised over crushed ice, quick frozen in liquid nitrogen, and stored at $-80^{\circ} \mathrm{C}$. High-performance liquid chromatography with electrochemical detection (Bioanalytical Systems, Inc.) was utilized to measure the concentrations of NE, 5-HT, 5-HIAA, and MHPG. Chemicals were purchased from SIGMA Chemical Company (St. Louis). Analyses were carried out using an Altex ultrasphere $5-\mu$ reverse phase $C-18$ column. The mobile phase contained $8.4 \mathrm{~g} / 1$ sodium acetate, $12 \mathrm{~g} / 1$ citric acid, $150 \mathrm{mg} / \mathrm{l}$ sodium octylsulfate, $200 \mathrm{mg}$ disodium EDTA, and $150 \mathrm{ml}$ methanol $(\mathrm{pH} \mathrm{4.0})$. The flow rate of the mobile phase was maintained at $1.0 \mathrm{ml} / \mathrm{min}$ at room temperature. The active electrode potential was set at $+0.60 \mathrm{~V}$. The detection limit for the monoamines assayed was approximately $25 \mathrm{pg}$ per sample injected.

Tissue samples were homogenized in $0.1 \mathrm{~N} \mathrm{HClO}_{4}(5 \% \mathrm{w} / \mathrm{vol})$ and centrifuged at $4^{\circ} \mathrm{C}$ at $10,000 \times g$ for $20 \mathrm{~min}$. One hundred $\mu \mathrm{l}$ of the supernatant was mixed with $100 \mu 1$ of 3,4 dihydroxy-benzylamine (DHBA) solution for internal standard. Fifty $\mu$ l. of the solution was directly injected onto the column for the determination of NE, 5 HT, and 5-HIAA. The rest of the supernatant was saved and frozen at $-80^{\circ} \mathrm{C}$ for the assay of MHPG. Recovery rates were $60 \%-80 \%$. The inter-assay and intra-assay coefficients of variation at $20 \mathrm{ng} / \mathrm{ml}$ were, respectively, $11 \%$ and $4 \%$ for NE, $9 \%$ and $3.5 \%$ for 5 -HIAA, and $10 \%$ and $6.5 \%$ for $5-\mathrm{HT}$.

Most MHPG in rat brain is sulfate conjugated, so it was hydrolyzed to free MHPG in order to be detected electrochemically. Two hundred fifty $\mu$ l of the supernatant for the MHPG assay was added to $0.25 \mathrm{ml}$ of $0.1 \mathrm{~N} \mathrm{HClO}_{4}$ in a screw-cap tube. After adding $0.05 \mathrm{ml}$ of $1 \mathrm{~N} \mathrm{HCl}$, the tube was heated at $80^{\circ}-90^{\circ} \mathrm{C}$ for $15 \mathrm{~min}$ To extract $\mathrm{MHPG}$ from the $\mathrm{HCl}$ phase, the sample was neutralized with $0.1 \mathrm{ml}$ of $1 \mathrm{M}$ Tris buffer, saturated with $\mathrm{NaCl}$ and mixed with $4 \mathrm{ml}$ of ethyl acetate. The sample was shaken for $15 \mathrm{~min}$ and centrifuged at $2,000 \times g$ for $5 \mathrm{~min}$. The ethyl acetate $(3.5 \mathrm{ml})$ was evaporated at $50^{\circ} \mathrm{C}$ under $\mathrm{N}_{2}$ in a Brinkman sample concentrator MHPG was extracted in $200 \mu \mathrm{l}$ of $0.1 \mathrm{M}$ formic acid, $50 \mu \mathrm{l}$ of which was injected onto the same $C-18$ reverse phase column used for the assay of NE, 5-HT, and 5-HIAA. The above procedures were done with 40,20 , and $10 \mathrm{ng} / \mathrm{ml}$ of $\mathrm{MHPG}-\mathrm{SO}_{4}$ for external standard curves. The inter-assay coefficient of variation was $13 \%$ at $10 \mathrm{ng} / \mathrm{ml}$. The same mobile phase was used at flow rate of $0.8 \mathrm{ml} / \mathrm{min}$. The working electrode potential was maintained at $0.85 \mathrm{~V}$.

\section{$\boldsymbol{\beta}$-Adrenoceptor Binding Assay}

The other hemisphere of the frontal cortex was used for $\beta$ adrenoceptor binding using a modification of the assay method of Hoyer, Engel, and Berthold (1982) performed with [125I] iodocyanopindolol ( ${ }^{125}$ ICYP). Two sample tissues were homogenized in ice-cold buffer ( $1: 40$ ratio) adjusted to $\mathrm{pH} 7.6$ with $\mathrm{HCl}$. The homogenate was centrifuged at $10,000 \times g$ for $20 \mathrm{~min}$ at $4^{\circ} \mathrm{C}$. One hundred milliliters of the brain homogenates were incubated with five different concentrations $(25,50,75,100$, and $150 \mathrm{pM})$ of ${ }^{125}$ ICYP in a final volume of $350 \mu$ incubation buffer containing $50 \mathrm{mM}$ Tris $\mathrm{HCl}, 145 \mathrm{mM} \mathrm{Nacl}$, and $5 \mathrm{mM} \mathrm{MgCl}_{2}$ for $30 \mathrm{~min}$ at $37^{\circ} \mathrm{C}$. Binding reaction was terminated by adding $6 \mathrm{ml}$ of Tris buffer at $37^{\circ} \mathrm{C}$ after rapid filtration through whatman glass fiber filters (934-AH) under vacuum. The filters were placed in vials containing $10 \mathrm{ml}$ of scintillation fluid. Filters were counted in a Beckman scintillation counter (Beckman Instruments, CA). Nonspecific binding was obtained by incubating the suspensions with $5 \mu \mathrm{l}$ of propranolol. Specific binding was defined as the difference between total binding and nonspecific binding. The maximum binding $\left(\mathrm{B}_{\mathrm{Max}}\right)$ and affinity $(\mathrm{Kd})$ values were determined using the method of McPherson (1985). 


\section{Citrate Synthase Assay}

To determine whether physical fitness was increased by the running conditions, hindlimb soleus muscle was sampled for citrate synthase activity, a measure of oxidative capacity in locomotory muscle. At the time of death, muscle samples were taken, frozen in liquid nitrogen, and stored at $-80^{\circ} \mathrm{C}$ until assayed. The activity of citrate synthase $(\mu \mathrm{mol} / \mathrm{min} / \mathrm{g}$ wet $\mathrm{wt})$ was assayed in muscle homogenates in duplicate by use of a spectrophotometric technique (Srere, 1969). A $50 \mu \mathrm{L}$ homogenate of muscle in $100 \mathrm{mM} \mathrm{KPO}_{4}(\mathrm{pH} \mathrm{7.4)}$ was diluted 1:25 with $100 \mathrm{mM}$ Tris buffer, $\mathrm{pH} 8.0$, and assayed spectrophotometrically using a Bausch and Lomb Spectronic Model 1001 at $412 \mathrm{~nm}$ and $30^{\circ} \mathrm{C}$.

\section{Statistical Analysis}

Data were analyzed using SPSS Windows Version 9.0 (SPSS Inc., Chicago). Means and standard deviations are reported in the text, and means and standard errors of the mean are reported in figures. Data were examined for normality. Mount latency and intromission latency were transformed by natural $\log$. Group differences in weekly body weight and kilometers run were compared using mixed-model repeated measures analysis of variance (ANOVA); $d f$ were adjusted for sphericity by Huynh-Feldt $\epsilon$. Frequencies of rats that copulated (i.e., made an intromission) or ejaculated were compared between groups by $\chi^{2}$ test ( $p<.05$, one-tailed). Group differences in male copulatory behavior and concentrations of $N E$, MHPG, 5-HT, and 5-HIAA, $\beta$-adrenergic receptor density and affinity, and citrate synthase activity were tested by one-way ANOVA $(p<.05)$. Strength of association was estimated by $\eta^{2}$. Effects were decomposed using Duncan's multiple range test $(p<.05)$. Simple effect sizes of interest were computed by the method of Cohen (1988), where $d=$ the mean difference between the sedentary CLI group and experimental groups divided by the sedentary CLI group standard deviation. $T$ tests were used to compare dependent variables between the sedentary CLI and saline control groups $(p<.05$; $d$ was computed using the saline control $S D$. Effect sizes $d$ approximating 0.25 to $0.50 S D$ were regarded as small to moderately large (Cohen, 1988).

A sample size of 9 per group provided a statistical power of 0.80 for detecting an effect size of $1.0 S D$ for all dependent variables at $p<.05$ (Cohen, 1988). We assigned 12 rats to each group, expecting an attrition of 2-3 animals per group. Final group sizes ranged from 9 to 12. Lost samples left group sizes of 5-6 for $\beta$-adrenoreceptor binding assays. Type III sums of squares were used for the repeated measures ANOVA.

\section{RESULTS}

The CLI treatment reduced the rate of male copulation. Increases in mount and intromission latencies, indexes of reduced sexual arousal or motivation, were consistent with the CLI model but were smaller than expected and not statistically significant. The activity wheel group performed better on the measures of copulatory performance but not motivation relative to the CLI sedentary group and most of the other treatment groups. Levels of NE were increased by activity wheel and treadmill running and by imipramine, but only the activity wheel and imipramine groups had a decrease in the number of $\beta$-adrenoceptors, consistent with pharmacological antidepressant effects. Citrate synthase activity in the soleus muscle, indicative of physical fitness, was higher in the each of the physically active groups than in all physically inactive groups. Groups did not differ in the MHPG/NE ratio, 5-HT levels, or the 5-HIAA/5-HT ratio, but the effect size for the
5-HIAA/5-HT ratio in the activity wheel group was large $(.90 S D)$.

\section{Copulatory Behavior}

Rater agreement on all copulatory behaviors was high $\left(R_{1}>.90\right)$, indicating that the test results were reliable. In general, there were two main findings. First, neonatal CLI treatment led to impaired copulatory behavior in the control animals (Table 1). Ten of the 12 rats in the saline control group made an intromission, whereas 5 of the 10 rats in the CLI sedentary group made an intromission $\left[\chi^{2}(1)=2.79, p<.05\right]$. Five saline-treated males ejaculated; 3 had multiple (2-3) ejaculations. In contrast, 3 CLI males ejaculated, and only 1 had 2 ejaculations. Table 2 shows that the sedentary CLI rats that did copulate had longer mount and intromission latencies, indicative of lower sexual arousal or motivation. Those effects did not reach statistical significance because of the low frequency of copulatory behaviors, but they were in the expected direction and small to moderate in size, consistent with previous findings of impaired male copulatory behavior in the CLI model (Neill, Vogel, Hagler, Kors, \& Hennessey, 1990; Vogel et al., 1996).

The second finding was that copulatory performance among the CLI-treated rats assigned to activity wheels was better than that of the other groups. Nine of the 10 rats in the activity wheel group made an intromission. That performance rate was similar to that of the saline control, imipramine, and imipramine + activity wheel groups, and it was superior to the sedentary $\left[\chi^{2}(1)=3.81, p=.024\right]$ and the treadmill $\left[\chi^{2}(1)=2.9, p=.04\right]$ CLI groups Eight rats in the activity wheel group ejaculated; 7 had $2-3$ ejaculations. The number of ejaculators in the activ-

Table 1

Rates in Each Group of Rats That Made an Intromission (Copulators) and Ejaculated

\begin{tabular}{ccccccc}
\hline Group & Sed & AW & IMP & IMP + AW & TM & Saline \\
\hline Copulators & $5 / 10$ & $9 / 10$ & $7 / 10$ & $7 / 11$ & $5 / 9$ & $10 / 12$ \\
Ejaculators & 3 & 8 & 1 & 4 & 2 & 5
\end{tabular}

Note-Sed, sedentary; AW, activity wheel: IMP, imipramine; TM, treadmill.

Table 2

Means $( \pm S D)$ and Effect Sizes $(d)$ Between the CLI-Treated Sedentary $(n=10)$ and the Saline Vehicle $(n=12)$ Groups on Mount Latency, Intromission Latency, Intromission Frequency (IF), Ejaculation Frequency (EF) for CLI $(n=5)$ and Saline $(n=10)$ Males That Copulated

\begin{tabular}{lccc}
\hline \multicolumn{1}{c}{$\begin{array}{c}\text { Copulatory } \\
\text { Behaviors }\end{array}$} & $\begin{array}{c}\text { CLl-Treated } \\
\text { Sedentary }\end{array}$ & $\begin{array}{c}\text { Saline } \\
\text { Vehicle }\end{array}$ & $\begin{array}{c}\text { Effect } \\
\text { Size }\end{array}$ \\
\hline Mount latency (sec) & $105 \pm 62$ & $86 \pm 72$ & 0.28 \\
Intromission latency (sec) & $271 \pm 195$ & $220 \pm 231$ & 0.23 \\
Mount frequency & $24.3 \pm 9.8$ & $26 \pm 10.9$ & 0.20 \\
Intromission frequency & $17.8 \pm 7.7$ & $18.3 \pm 8.2$ & 0.06 \\
Ejaculation frequency & $0.67 \pm 0.8$ & $0.80 \pm 0.9$ & 0.15 \\
Postejaculatory interval (sec) & $297 \pm 76$ & $316 \pm 38$ & 0.35 \\
IF/EJF & $16.3 \pm 2.1$ & $16.9 \pm 8.6$ & 0.09 \\
\hline
\end{tabular}

Note-Postejaculatory interval and IF/EF for CLI $(n=3)$ and saline $(n=5)$ males that ejaculated. 
ity wheel group was higher than in the sedentary CLI $\left[\chi^{2}(1)=5.05, p=.015\right]$ and saline $\left[\chi^{2}(1)=3.31, p=\right.$ $.03]$ control groups and all other interventions groups $(p<.05)$, as shown in Table 1.

Among copulators, there were group effects for mount frequency $\left[F(5,38)=2.4, \eta^{2}=.235, p=.05\right]$, intromission frequency $\left[F(5,38)=3.24, \eta^{2}=.299, p=\right.$ $.016]$, and ejaculation frequency $\left[F(5,38)=2.46, \eta^{2}=\right.$ $.244, p=.05$ ] (see Figures 1-3). However, among rats that ejaculated there were no group differences in the postejaculatory interval $\left[F(5,17)=1.81, \eta^{2}=.05, p=\right.$ $.996]$ or in the number of intromissions per ejaculation $\left[F(5,17)=0.478, \eta^{2}=.123, p=.787\right]$. Post hoc tests indicated that among copulators, mount frequency was higher in the activity wheel runners than in all other groups. Intromission frequency among the activity wheel

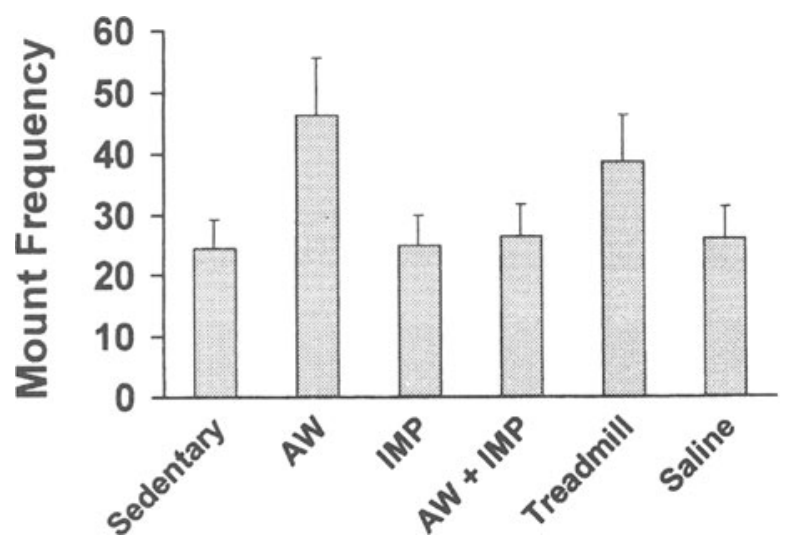

Figure 1. Mount frequency among Sprague-Dawley adult males that copulated after neonatal treatment with clomipramine, compared with a saline vehicle control group $(n=9-12)$. Frequency was higher in the activity wheel group than in all other groups $(p<.05)$.

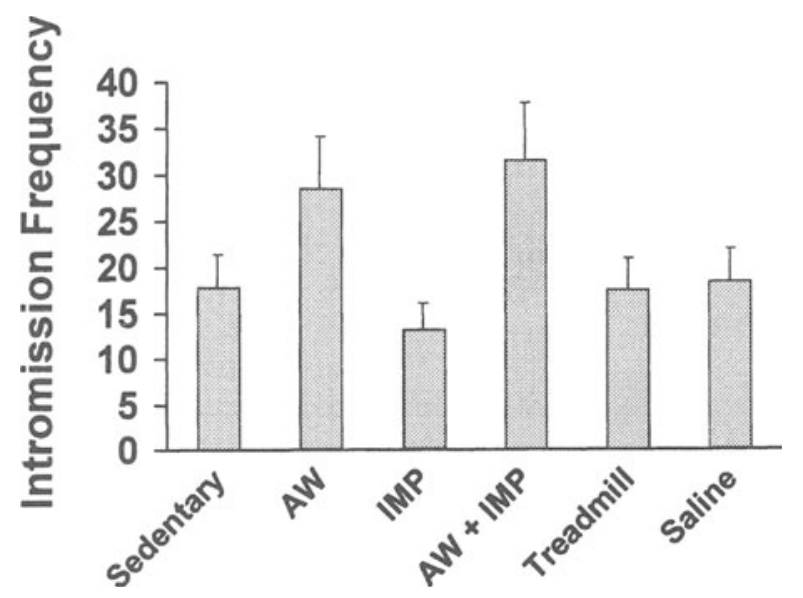

Figure 2. Intromission frequency was higher in the activity wheel and activity wheel + imipramine groups than in other groups $(p<.05)$.

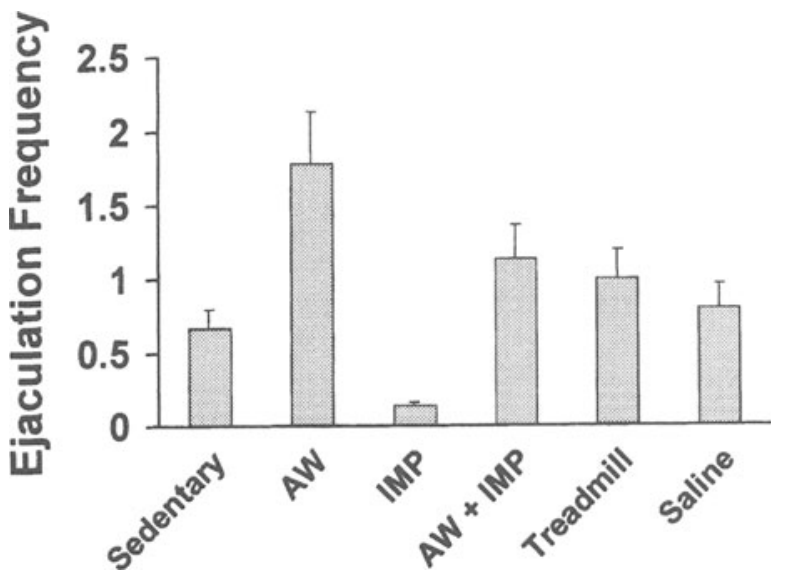

Figure 3. Ejaculation frequency was highest in the activity wheel group and lowest in the imipramine group, compared with all other groups $(p<.05)$.

group and the activity wheel + imipramine group was higher than in all other groups. Ejaculation frequency was higher in the activity wheel runners and lower in the imipramine group relative to all other groups. There were no group effects for mount latency $\left[F(5,38)=0.82, \eta^{2}=\right.$ $.10, p=.543]$ or intromission latency $[F(5,38)=1.33$, $\left.\eta^{2}=.149, p=.272\right]$.

\section{NE, MHPG, 5-HT, and 5-HLAA in Frontal Cortex}

There was a group effect for NE level $[F(5,56)=$ $2.94, \eta^{2}=.208, p=.02$; Figure 4$]$. The activity wheel, the treadmill, and the imipramine groups had higher levels than the CLI sedentary group. NE level in the wheel + imipramine group was higher than in the CLI sedentary and the saline vehicle groups. There was no difference between groups for levels of MHPG $[F(5,56)=$ $\left.0.596, \eta^{2}=.051, p=.703\right], 5-\mathrm{HT}[F(5,56)=0.280$, $\left.\eta^{2}=.024, p=.922\right]$, and 5-HIAA $\left[F(5,56)=2.01, \eta^{2}=\right.$ $.152, p=.091]$. The activity wheel group had large effect sizes $(d)$ for MHPG (.60) and 5-HIAA (1.55) levels.

No significant effects were obtained for MHPG/NE $\left[F(5,56)=0.769, \eta^{2}=.065, p=.576\right]$ or 5 -HIAA $/ 5-\mathrm{HT}$ $\left[F(5,56)=1.78, \eta^{2}=.137, p=.131\right]$, but the effect sizes (d) for the 5-HIAA/5-HT ratio were large in the activity wheel runners $(.90)$ and moderately large in the treadmilltrained groups (.50). See Figure 5.

Simple effects comparing the sedentary CLI group with the sedentary saline control group did not reach statistical significance, but Table 3 shows that effects for NE, MHPG, and 5-HIAA were moderately large (.33-.40 $S D$ ), suggesting that CLI tended to suppress levels of $\mathrm{NE}$ and monoamine metabolites.

\section{$\boldsymbol{\beta}$-Adrenoreceptor Receptor Binding}

There were group differences in receptor density $\left(\mathrm{B}_{\mathrm{Max}}\right)\left[F(5,24)=3.69, \eta^{2}=.435, p=.013\right.$; see Figure 6]. The post hoc tests showed that the imipramine, the activity wheel + imipramine, and the activity wheel 


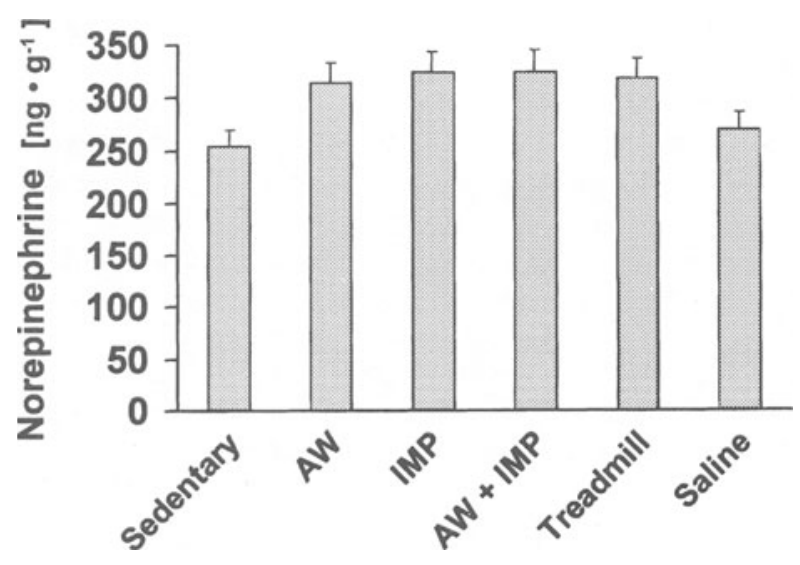

Figure 4. Concentration levels of norepinephrine (NE) in brain frontal cortex among Sprague-Dawley adult males treated neonatally with clomipramine compared with a saline vehicle control group $(n=9-12)$. Levels in the activity wheel, treadmill, and imipramine groups were higher than in the sedentary control group $(p<.05)$. Level in the wheel + imipramine group was higher than in the sedentary control and saline vehicle groups $(p<.05)$.

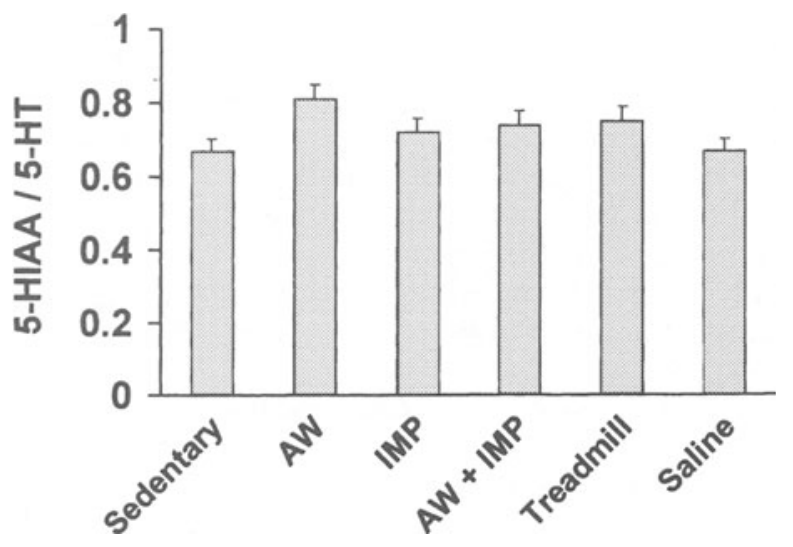

Figure 5. Ratio of concentration levels of 5-HIAA/5-HT in brain frontal cortex among Sprague-Dawley adult males treated neonatally with clomipramine compared with a saline vehicle control group $(n=9-12)$. ANOVA did not reach statistical significance ( $p=.13$ ), but the effect size comparing the activity wheel group with the sedentary control group was large $(.90 S D)$.

groups were lower than the CLI sedentary and the saline vehicle groups. No group differences were seen for $\beta$ adrenoceptor affinity $\left(\mathrm{K}_{\mathrm{D}}\right)\left[F(5,24)=1.03, \eta^{2}=.176\right.$, $p=.425]$.

\section{Body Mass}

A group effect $\left[F(5,56)=11.6, \eta^{2}=.509, p<.001\right]$ indicated that the saline vehicle group had higher body mass than all five experimental groups at the time of group assignment when rats were 4 weeks old. That difference persisted until the end of the experiment, indicating neonatal CLI injection negatively affected weight gain. A group $\times$ time effect $\left[F(55,616)=7.73, \eta^{2}=\right.$
$.408, \epsilon=.175, p<.001]$ indicated that weight did not differ among the experimental CLI groups through Week 6. At Week 7, the imipramine, treadmill, and CLI sedentary groups had higher weights $(411-430 \mathrm{~g})$ than the activity wheel and the wheel + imipramine groups $(\sim 375 \mathrm{~g})$. That difference remained through Week 11 until death, when mass differed $(p<.05)$ as follows: wheel + imipramine $(442 \mathrm{~g})$ and wheel $(472 \mathrm{~g})<$ imipramine $(508 \mathrm{~g})<$ treadmill $(522 \mathrm{~g})$ and sedentary CLI $(550 \mathrm{~g})<$ sedentary saline control $(596 \mathrm{~g})$.

\section{Running Distance}

The activity wheel and the wheel + imipramine groups did not differ in mean weekly running distance throughout the experimental period $\left[F(11,209)=0.379, \eta^{2}=\right.$ $.020, \epsilon=.424, p=.850]$. A time effect $[F(11,209)=$ $\left.22.78, \eta^{2}=.545, \epsilon=.424, p<.001\right]$ indicated that the activity wheel and the wheel + imipramine group's running peaked during Weeks 6-8 (about $50 \mathrm{~km}$ ). Those groups were running nearly three times the weekly distance of the treadmill group during that period.

\section{Citrate Synthase Activity}

Citrate synthase activity ( $\mu \mathrm{mol} / \mathrm{min} / \mathrm{g}$ wet weight) in soleus muscle differed according to group $[F(5,50)=$ $\left.17.39, \eta^{2}=.635, p<.001\right]$. It was higher in the activity wheel $(44 \pm 6)$, the wheel + imipramine $(42 \pm 6)$, and the treadmill $(51 \pm 5)$ groups than in the sedentary, the imipramine, and the saline vehicle groups $(\sim 36 \pm 3)(p<$ $.05)$. The treadmill group had higher levels than the activity wheel and the wheel + imipramine groups $(p<$ $.05)$. The Pearson correlation coefficient $(r)$ between citrate synthase activity in soleus muscle and wheel running distance during the last 3 weeks was $.50(\mathrm{p}<.01)$. Citrate synthase activity was weakly correlated with levels of NE $(r=.31, p=.08)$ and 5-HIAA $(r=.33, p=.07)$.

\section{DISCUSSION}

Chronic activity wheel runners had enhanced copulatory performance, consistent with their brain noradrenergic adaptations. There were two main findings for copulatory behavior. The first finding was that the neonatal CLI treatment led to impaired copulation in the control

Table 3

Means $( \pm S D$ ) and Effect Sizes $(d)$ Between the CLI-Treated Sedentary and the Saline Vehicle Groups for NE, MHPG, 5-HT, 5-HIAA, MHPG/NE, 5-HIAA/5-HT, and $\beta$-adrenoceptor number $\left(B_{\text {Max }}\right)$ and Affinity $\left(K_{p}\right)$

\begin{tabular}{lccc}
\hline & $\begin{array}{c}\text { CLI-Treated } \\
\text { Sedentary }(n=10)\end{array}$ & $\begin{array}{c}\text { Saline } \\
\text { Vehicle }(n=12)\end{array}$ & $\begin{array}{c}\text { Effect } \\
\text { Size }\end{array}$ \\
\hline NE & $253.49 \pm 57.7$ & $269.51 \pm 41.2$ & 0.40 \\
MHPG & $211.77 \pm 128$ & $266.69 \pm 137.8$ & 0.40 \\
5-HT & $415.70 \pm 98.2$ & $444.20 \pm 121.4$ & 0.23 \\
5-HIAA & $269.87 \pm 51.2$ & $297.2 \pm 83.7$ & 0.33 \\
MHPG/NE & $0.84 \pm 0.50$ & $1.00 \pm 0.56$ & 0.30 \\
5-HIAA/5-HT & $0.67 \pm 0.15$ & $0.67 \pm 0.08$ & 0.00 \\
B $_{\text {Max }}$ & $3.99 \pm 1.18$ & $3.90 \pm 1.8$ & 0.05 \\
K $_{\mathrm{D}}$ & $298 \pm 139.5$ & $307 \pm 116.8$ & 0.08 \\
\hline
\end{tabular}




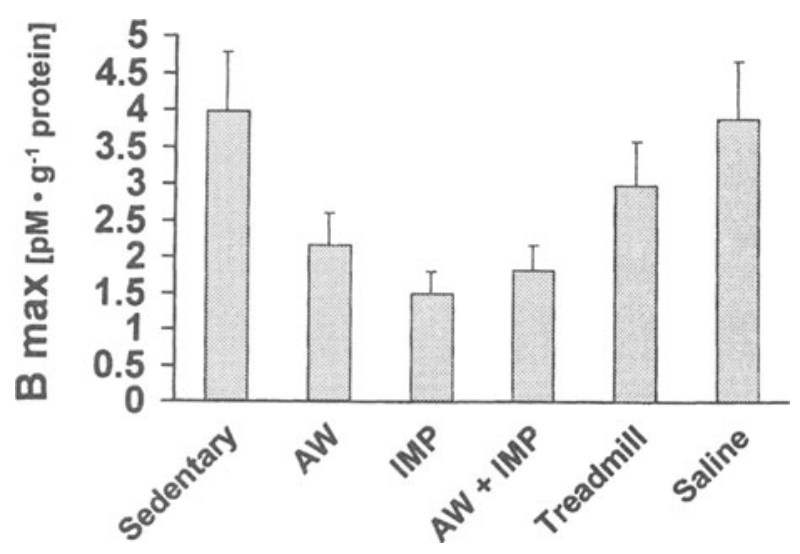

Figure 6. Radioligand $\left[{ }^{125} I\right]$ binding density $\left(B_{\mathrm{Max}}\right)$ of $\beta$ adrenoceptors in brain frontal cortex among Sprague-Dawley adult males treated neonatally with clomipramine compared with a saline vehicle control group $(n=5-6)$. B Max $_{\text {as lower for }}$ the activity wheel, imipramine, and wheel running + imipramine groups compared with the sedentary $C L I$ and saline vehicle control groups $(p<.05)$.

animals. Only half the males in the CLI sedentary group made an intromission, whereas 10 of 12 rats in the saline control group copulated. Five saline treated males ejaculated; 3 had multiple ejaculations. In contrast, only 1 of the 3 CLI males that ejaculated had more than 1 ejaculation. Results for other measures of copulatory performance were mixed and smaller than expected. The sedentary CLI rats that did copulate had longer mount and intromission latencies, indicative of lower sexual arousal or motivation, but the effects did not reach statistical significance. The relatively poor performance by the saline controls led to low statistical power, but it was not feasible to prescreen the animals for good copulators prior to experimental assignment. Future studies like this might benefit from using a more sexually active strain (e.g., Long-Evans) and replacing the females after each series to minimize the Coolidge effect.

The second finding was that copulatory performance among the CLI-treated rats assigned to activity wheels was better than that of the other groups. Nine of 10 rats in the activity wheel group made an intromission. That performance rate was similar to that of the saline control, imipramine, and imipramine + AW groups, and it was superior to that of the sedentary and the treadmill groups. Eight rats in the activity wheel group ejaculated, and 7 had 2-3 ejaculations; these were higher rates than for all other groups. Moreover, copulation among activity wheel runners who received imipramine treatment was similarly high, despite the unexpectedly low copulation rate by the males that received imipramine and were sedentary. Rather than an expected additive effect of wheel running and imipramine, our results indicate that wheel running protected against copulatory impairment induced by the imipramine treatment. Activity wheel running en- hanced copulatory performance but did not affect the indexes of sexual arousal or motivation.

Though the noradrenergic adaptations and enhanced sexual performance after activity wheel running were pronounced, other aspects of our results preclude a clear interpretation that they represent an antidepressant effect, rather than a nonspecific noradrenergic adaptation. In a companion paper from this study, we have reported no effects of the CLI treatment or the running conditions on forced swim immobility (Yoo, Bunnell, Crabbe, Kalish, \& Dishman, 2000). The validity of the CLI model has not been established using measures of brain monoamines and receptor changes assessed concomitantly with behavioral signs of depression that mimic the anhedonia that is characteristic of human depression. A recent report indicated that decreased levels of NE and 5HT in frontal cortex after neonatal CLI injection were accompanied by decreased aggression and food intake (Vijayakumar \& Meti, 1999). However, the specificity of those behavioral signs as indicants of a depression-like response has not been established within the CLI model. Previous reports of impaired masculine sexual behavior after neonatal CLI treatment (Bonilla-Jaime et al., 1998; Vogel et al., 1996; Vogel, Neill, Hagler, \& Kors, 1990) reported equivalent impairments for measures of arousal or motivation and performance. The influence of neonatal CLI treatment on male copulatory behavior and its meaning for the modeling of depression might be clarified by direct comparison with another endogenous model of depression (e.g., olfactory bulbectomy, Kelly, Wrynn, \& Leonard, 1997) known to alter monoamine systems and depression-like behaviors, including masculine sexual behavior (Lumia, Lebrowski, \& McGinnis, 1987).

Signs of CLI-induced impairment of male copulatory behavior first appear at age 3 months and are maximized at age 5 months (Bonilla-Jaime et al., 1998; Vogel et al., 1996) to 7 months (Neill et al., 1990; Vogel, Neill, Hagler, \& Kors, 1990). We tested copulatory behavior at 4 months of age to avoid an exercise detraining effect, as wheel running by Sprague-Dawley males in our protocol typically peaks during Weeks 6-8 after introduction to the wheels ( 3 months of age) and decreases thereafter (Dunn et al., 1996). Male sexual impairment after neonatal CLI treatment is dose dependent, but the 40-mg dose we used has been reliably effective in other strains (Vogel et al., 1996). In our experience, higher doses are accompanied by gastrointestinal side effects.

As far as we know, this is the first report of an independent effect of chronic physical activity in reducing brain $\beta$-adrenoceptor density, a hallmark of antidepressantinduced neural adaptation (Baldessarini, 1989). A prior study that reported no effect on $\beta$-adrenoreceptor binding after wheel running confounded circadian physical activity with operant conditioning and assayed a whole hemisphere (deCastro \& Duncan, 1985). Presently, $\beta$ adrenoreceptor density was decreased in the activity 
wheel, the activity wheel + imipramine, and the imipramine groups. Since impaired copulatory behavior is regarded as a valid sign of depression, the therapeutic meaning of the down-regulated $\beta$-adrerenoceptors presently observed is unclear. The activity wheel + imipramine and the imipramine groups demonstrated low copulatory behavior. The down regulation of $\beta$-adrerenoceptor density can be largely attributed to increased synaptic NE concentration in the frontal cortex. Higher levels of NE in the brain frontal cortex were observed in the activity wheel, the imipramine, the activity wheel + imipramine, and the treadmill-trained groups than in the CLI sedentary animals. However, the density of $\beta$-adrerenoceptors was markedly lower in the activity wheel group $(d=$ $1.55)$ than in the treadmill group $(d=0.85)$. Hence, NE levels cannot solely explain the more pronounced decrease in $\mathrm{B}_{\mathrm{Max}}$ among the wheel runners. Increased 5-HT activity may have contributed to the $\beta$-adrenergic down regulation in the activity wheel group.

Serotonergic activity down regulates $\beta$-adrenoceptors in the frontal cortex of rats (Stockmeier, Martino, \& Kellar, 1985), and it appears that a functional 5-HT system is required for the down regulation of the $\beta$-adrenoceptors during chronic administration of tricyclics (Brunello, Chuang, \& Costa, 1982; Racagni, Moccetti, Calderini, Battistella, \& Brunello, 1983). Presently, levels of 5-HT and 5-HIAA and the ratio of 5-HIAA/5-HT, an index of serotonergic activity, in the frontal cortex were not statistically different between groups. However, effect sizes (d) for the 5-HIAA/5-HT ratio were largest in the activity wheel group (.90), followed by the treadmill $(.50)$ and the activity wheel + imipramine (.40) groups. This pattern, in conjunction with similar results for 5-HIAA level, is consistent with that of a previous study (Dey et al., 1992) indicating that 5-HT activity is increased following chronic exercise. Consistent with other research, levels of MHPG were not changed by imipramine treatment (Sugrue, 1983).

Other chronic stressors reduce the number of $\beta$ adrenoceptors (Stanford, 1990), but the effect size $(d)$ we observed after wheel running (1.55) was nearly twice that observed after forced treadmill running $(.85)$. Hence, we do not believe the reduction that we report after voluntary wheel running can be attributed to chronic stress. Down regulation of $\beta$-adrenoceptors in the frontal cortex is expected after imipramine treatment (Duncan et al., 1985; Papp, Nalepa, \& Vetulani, 1994). A greater down regulation of $\beta$-adrenoceptors by imipramine combined with acute swim stress (Paul et al., 1990) has been reported, suggesting that a combination of pharmacotherapy with exercise stress could be therapeutically useful (Duncan et al., 1993). However, our findings indicate that the effects of activity wheel running were not additive with those of imipramine.

To our knowledge, the present report is the first to compare voluntary chronic physical activity with pharmacotherapy within a depression model. The imipramine treatment did not improve copulatory behavior. Whereas 7 of 10 imipramine-treated males made intromissions, only one ejaculated, whereas at least half the males in the other groups that made an intromission ejaculated. As pharmacological studies have revealed that clinical improvement of depression occurs within 2-3 weeks of antidepressant treatment in humans (Baldessarini, 1989), our 10 days of imipramine treatment $(10 \mathrm{mg} / \mathrm{kg}$ twice daily) may have been too short. However, another study that used a similar regimen of imipramine treatment ( $10 \mathrm{mg} / \mathrm{kg}$ twice daily for 4 days) reported attenuated sexual deficiencies in CLI-treated Long-Evans rats (Vogel, Neill, Hagler, \& Kors, 1990). Optimal dosing for enhancing male copulatory behavior requires more study. Abnormalities of 5-HT function have been linked to several depressive signs, such as loss of appetite, sleep disturbance, and sexual dysfunction (Fuller, 1995), whereas abnormalities of NE function tend to be related to psychomotor features of depression (Feldman, Meyer, \& Quenzer, 1997). Thus, chronic treatment with imipramine might affect psychomotor activity more than motivational features of male copulatory behavior in rats. A comparison of effects between reuptake inhibitors selective for serotonin versus $\mathrm{NE}$ among sexually impaired animals needs to be studied.

Our results show that enhanced male copulatory behavior was independent of increased physical fitness. Increased citrate synthase activity confirmed the expected exercise training adaptations after treadmill exercise training and activity wheel running, yet only the activity wheel runners had enhanced copulatory performance. The forced treadmill training showed no effect on copulatory behavior, with the exception of a shorter mount latency. This is difficult to interpret. One explanation might involve psychological stress associated with forced treadmill exercise. We did not use electrical shock, and treadmill training was conducted during the dark photoperiod in order to minimize circadian stress during treadmill running. Although the animals generally were good runners (White-Welkley, Bunnell, Mougey, Meyerhoff, \& Dishman, 1995), the forced nature of motorized treadmill running is undoubtedly stressful. Chronic stress, including sustained heavy exercise, has been associated with hypercortisolism, which can stimulate catecholamine responsiveness (Sapolsky, 1992). Elevated sympathoadrenal capacity has been observed in highly trained human males (Kjaer, 1992). Thus, it is possible that chronic treadmill training in rat might lead to an altered sympathovagal balance. Inhibition of parasympathetic tone could impair an initial erection (Sapolsky, 1992). Though speculative, this idea is consistent with our raters' observation that treadmill-trained rats showed the shortest mean mount latency among all groups $(d=.70 S D)$, but many of them failed to achieve intromission.

Genomic changes in monoamine neurons after CLI treatment need to be examined after chronic physical activity (see, e.g., Hansen \& Mikkelsen, 1998). The medial preoptic area, which is critical for male sexual behavior, also should be studied. Future exercise studies that use 
the CLI model might lengthen the training period to 6 months or assign rats to each treatment condition at an older age in order to optimize differences between control and experimental groups. We selected a treadmill training protocol known to increase fitness; however, other treadmill protocols (e.g., lower speed and shorter duration) might be preferred in order to elicit antidepressant effects.

In conclusion, voluntary activity wheel running enhanced male copulatory performance but not indicants of sexual arousal or motivation. The mechanism for those effects is not clear, since the effects of CLI treatment were largest for sexual arousal rather than for performance. Consistent with psychopharmacological models of depression, CLI treatment reduced NE levels, while the increased NE levels and reduced $\beta$-adrenoceptor density after wheel running were independent of, equal to, and nonadditive with effects of imipramine. Pharmacological evidence from sedentary rats has suggested that neonatal treatment with CLI induces sexual deficits by acting mainly on the adrenergic and cholinergic systems, while the serotonergic system seems to be unaffected (Bonilla-Jaime et al., 1998). Alternatively, electrophysiological evidence suggests that the CLI model induces a reduction in the tonic discharge rate of dorsal raphe 5-HT neurons (Kinney et al., 1997; Yavari et al., 1993). Consistent with those results, the presently observed effect of wheel running on the 5-HIAA/5-HT ratio suggests that increased serotonergic activity in the brain frontal cortex might be a putative factor in the reduction in $\beta$-adrenoceptor density and the concomitant enhancement of copulatory performance observed among activity wheel runners treated neonatally with CLI.

\section{REFERENCES}

American Psychiatric Association (2000). Practice guidelines for the treatment of patients with major depressive disorder (revision). The American Journal of Psychiatry, 157, (Suppl. 4), 1-45.Washington, DC: Author.

armstrong. R. B., Laughlin, M. H.. Rome, L., \& Taylor, C. R. (1983). Metabolism of rats running up and down an incline. Journal of Applied Physiology, 55, 518-521.

Baldessarini. R. J. (1989). Current status of antidepressants: Clinical pharmacology and therapy. Journal of Clinical Psychiatry, 50, 117-126.

Blomstrand, E., Perrett, D., Parry-Blllings, M., \& Newsholme, E. A. ( I989). Effect of sustained exercise on plasma amino acid concentrations and on 5-hydroxytryptamine metabolism in six different brain regions in the rat. Acta Physiologica Scandinavica, 136, 473-481.

Bonilla-Jaime, H., Retana-Marquez, S., \& Velazquez-Moctezuma, J. (1998). Pharmacological features of masculine sexual behavior in an animal model of depression. Pharmacologv, Biochemistry \& Behavior, 60, 39-45.

Broocks, A., Liu, J., \& Pirke, K. M. (1990). Semistarvation-induced hyperactivity compensates for decreased norepinephrine and dopamine turnover in the mediobasal hypothalamus of the rat. Journal of Neural Transmission, 79, 113-124.

Brown, B. S., Payne, T., Kim, C., Moore, G., Krebs, P., \& Martin, W. (1979). Chronic response of rat brain norepinephrine and serotonin levels to endurance training. Journal of Applied Physiology, 46, 19-23.

Brown, B. S., \& VAN Huss, W. (1973). Exercise and rat brain catecholamines. Journal of Applied Physiologv, 34, 664-669.

Brunello, N., Chuang, D. M., \& Costa, P. I. (1982). Use of specific brain lesions to study the site of action of antidepressants. Advanced Bioscience, 40, 141-145.

Cenci, M. A., Kalen, P., Mandel, R. J., \& Bjorkland, A. (1992). Regional differences in the regulation of dopamine and noradrenaline release in the medial frontal cortex, nucleus accumbens and caudateputamen: A microdialysis study in the rat. Brain Research, 581, 217-228.

Chaouloff, R., Laude, D., Serrurrier, D., Merino, Guezennec, Y., \& Elghozi, J. L. (1987). Brain serotonin response to exercise in the rat: The influence of training duration. Biogenic Amines, 4, 99-106.

COHEN, J. (1988). $F$ tests on means in the analysis of variance and covariance. In J. Cohen (Ed.), Statistical power analysis for the behavioral sciences (pp. 381-388). Hillsdale, NJ: Erlbaum.

DECASTRO, J. M., \& DUNCAN, G. (1985). Operantly conditioned running: Effects of brain catecholamine concentrations and receptor densities in the rat. Pharmacology. Biochemistry \& Behavior, 23, 495-500.

DEWSBURY, D. A. (1967). A quantitative description of the behavior of rats during copulation. Behaviour, 29, 154-178.

DEY, S., SingH.. R. H., \& DEY, P. K. (1992). Exercise training: Signifi cance of regional alterations in serotonin metabolism of rat brain in relation to antidepressant effect of exercise. Physiology \& Behavior. 52, 1095-1099.

Dishman, R. K., Renner, K. J., Youngistedt, S. D., Reigle, B. N., Bunnell, B. N., Burke, K. A., Yoo, H. S., Mougey, E. H., \& MeYerHOFF, J. L. (1997). Activity wheel running reduces escape latency and alters brain monoamines after footshock. Brain Research Bulletin, 5. 399-406.

Drugan, R. C., Ryan, S. M., Minor, T. R., \& Maier, S. F. ( 984 ). Librium prevents the analgesia and shuttlebox escape deficit typically observed following inescapable shock. Pharmacology. Biochemistry \& Behavior, 21, 749-754.

Duncan. G. E., Paul, I. A.. \& Breese, G. R. (1993). Neuroanatomical differences in the rate of beta-adrenergic receptor adaptation after repeated treatment with imipramine. Psychopharmacology Bulletin, 29, $401-407$.

Duncan, G. E., Paul, I. A., Harden, K., Mueller, R. A., Stumpf, W. E., \& BREESE, G. R. (1985). Rapid down regulation of beta adrenergic receptors by combining antidepressant drugs with forced swim: A model of antidepressant-induced neural adaptation. Journal of Pharmacology \& Experimental Therapeutics, 234, 402-408.

Dunn, A. L., \& Dishman, R. K. (1991). Exercise and the neurobiology of depression. Exercise \& Sport Sciences Reviews, 19, 41-98.

Dunn, A. L., Reigle., T. G., Youngstedt. S. D.. Armstrong. R. B.. \& DishMAN. R. K. (1996). Brain norepinephrine and metabolites after treadmill training and wheel running in rats. Medicine \& Science in Sports \& Exercise, 28, 204-209.

Elam, M., Svensson, T. H.. \& Thoren. P. (1987). Brain monoamine metabolism is altered in rats following spontaneous, long-distance running. Acta Physiological Scandinavica, 130, 313-316.

Feldman, R. S., Meyer, J. S., \& Quenzer, L. F. (1997). Principles of neuropsychopharmacology. Sunderland, MA: Sinauer.

Foote, S. L., Bloom, F. E., \& Aston-Jones. G. ( 1983 ). Nucleus locus ceruleus: New evidence of anatomical and physiological specificity. Physiological Reviews, 63, 844-914.

FULLER, R. W. (1995). Serotonin uptake inhibitors: Uses in clinical therapy and in laboratory research. Progress in Drug Research, 45, 167-204.

Glavin, G. B. (1985). Stress and brain noradrenaline: A review. Neuroscience \& Biobehavioral Reviews, 9, 233-243.

Gray, J. A. (1985). Issues in the neuropsychology of anxiety. In A. H. Tuma \& J. D. Masser (Eds), Anxiety and the anxiety disorders (pp. 5 26). Hillsdale, NJ: Erlbaum.

HANSEN, H. H., \& MiKKELSEN. J. D. (1998). Long-term effects on serotonin transporter mRNA expression of chronic neonatal exposure to a serotonin reuptake inhibitor. European Journal of Pharmacologv. 352, 307-315.

harris, S. S., Caspersen, C. J., Defriese, G. H., \& Estes, E. H.. JR. (1989). Physical activity counseling for healthy adults as a primary preventive intervention in the clinical setting. Journal of the American Medical Association, 261, 3590-3598.

Heinsbroek, R. P. W., van Haaren, F., Feenstra, M. G. P.. Boon. P., 
\& VAN POLL, N. E. (1991). Controllable and uncontrollable footshock and monoaminergic activity in the frontal cortex of male and female rats. Brain Research, 551, 247-255.

Hellhammer, D. H., Hingtgen, J. N., Wade, S. E., Shea, P. A., \& APRISON, M. H. (1983). Serotonergic changes in specific areas of rat brain associated with activity-stress gastric lesions. Psychosomatic Medicine, 45, 115-122.

HoleTs, V. R. (1990). The anatomy and function of noradrenaline in the mammalian brain. In D. J. Heal \& C. A. Marsden (Eds.), The pharmacology of noradrenaline in the central nervous system (pp. 1-40). Oxford: Oxford University Press.

Hoyer, D., Engel, G., \& BerThold, R. (1982). Binding characteristics of $(+)-,( \pm)$ - and (-)-[125lodo] cyanopindolol to Guinea pig left ventricle membranes. Naunyn-Schmiedeberg's Archives of Pharmacology, 318, 319-329.

Kelly, J. P.. WRYNN, A. S., \& LeONARD, B. E. (1997). The olfactory bulbectomized rat as a model of depression: An update. Pharmacology \& Therapeutics, 74, 299-316.

KinNey, G. G., Vogel, G. W., \& FenG, P. (1997). Decreased dorsal raphe nucleus neuronal activity in adult chloral hydrate anesthetized rats following neonatal clomipramine treatment: Implications for endogenous depression. Brain Research, 756, 68-75.

KJAER, M. (1992). Regulation of hormonal and metabolic response during exercise in humans. Exercise \& Sport Sciences Reviews, 20, 161-184.

KоOв, G. F. (1989). Anhedonia as an animal model of depression. In G. F. Koob, C. L. Ehlers, \& D. J. Kupfer (Eds.), Animal models of depression (pp. 162-183). Boston: Birkhauser.

LUMIA, A. R., LEbrowski, A. F., \& MCGinNIS, M. Y. (1987). Olfactory bulb removal decreases androgen receptor binding in amygdala and hypothalamus and disrupts masculine sexual behavior. Brain Research, 404, 121-126.

Martinsen, E. W.. \& Stanghelle, J. K. (1997). Drug therapy and physical activity. In W. P. Morgan (Ed.), Physical activity and mental health (pp. 81-90). Washington, DC: Taylor \& Francis.

McDonald, D. G., \& Hodgdon, J. A. (1991). The psychological effects of aerobic fitness training: Research and theory. New York: Springer-Verlag.

McPherson, G. A. (1985). Analysis of radioligand binding experiments: A collection of computer programs for the IBM PC. Journal of Pharmacology Methods, 14, 21 3-228.

Mirmaran, M., Van de Poll, N. E., Corner, H. G., Van Oyen, H., \& BOER, G. (1981). Suppression of active sleep by chronic treatment with clomipramine during early postnatal development: Effect on adult sleep and behavior in the rat. Brain Research, 204, 129-146.

Morgan, W. P. (1994). Physical activity, fitness, and depression. In C. Bouchard, R. J. Shephard, \& T. Stephens (Eds.), Physical activity and health: International proceedings and consensus statement (pp. 851-867). Champaign, IL: Human Kinetics.

Neill, D., Vogel, G., Hagler, M., Kors, D., \& Hennessey, A. (1990). Diminished sexual activity in a new animal model of endogenous depression. Neuroscience \& Biobehavioral Reviews, 14, 73-76.

North, T. C., McCullagh, P., \& Vu Tran, Z. (1990). Effects of exercise on depression. Exercise \& Sport Sciences Reviews, 18, 379-415.

Ostman, I., \& Nrback, H. (1976). Adaptive changes in central and peripheral noradrenergic neurons in rats following chronic exercise. Neuroscience, 1, 41-47.

PaPP, M., NAlePa, I., \& Vetulani, J. (1994). Reversal by imipramine of $\beta$-adrenoreceptor up-regulation induced in a chronic mild stress model of depression. European Journal of Pharmacology, 262, 141-147.

Paul, I. A., Duncan, G. E., Kuhn, C., Mueller, R. A., Hong, J-S., \& BREESE, G. R. (1990). Neural adaptation in imipramine-treated rats processed in forced swim test: Assessment of time course, handling, rat strain and amine uptake. Journal of Pharmacology \& Experimental Therapeutics, 252, 997-1005.

Racagni, G., Moccetti, I., Caiderini, G., Battistella, A., \& BRUNELLo, N. (1983). Temporal sequence of changes in central noradrenergic system of rat after prolonged antidepressant treatment: Receptor desensitization and neurotransmitter interactions. Neuropharmacology, 22, 415-424

RANSFORD, C. P. (1982). A role for amines in the antidepressant effect of exercise: A review. Medicine \& Science in Sports \& Exercise, 14, 1-14.
Rea, M. A., \& Hellhammer, D. H. (1984). Activity wheel stress changes in brain norepinephrine turnover and the occurrence of gastric lesions. Psychotherapy \& Psychosomatics, 42, 218-223.

SAPOLSKY, R. M. (1992). Neuroendocrinology of the stress-response. In J. B. Becker, S. M. Breedlove, \& D. Crews (Eds.), Behavioral endocrinology (pp. 287-324). Cambridge, MA: MIT Press.

Simons, A. D., Epstein, L. H., McGowan, C. R., Kupfer, D. J., \& Robertson, R. J. (1985). Exercise as a treatment for depression. Clinical Psychology Reviews, 5, 553-568.

Soares, J., Holmes, P. V., Renner, K. J., Edwards, G. L., Bunnell, B. N., \& DishmaN, R. K. (1999). Brain noradrenergic responses to footshock after chronic activity-wheel running. Behavioral Neuroscience, 113, 558-566.

Sothmann, M. S., Buckworth, J., Claytor, R. P., Cox, R. H. White-Welkley, J. E., \& Dishman, R. K. (1996). Exercise training and the cross-stressor adaptation hypothesis. Exercise \& Sport Sciences Reviews, 24, 267-287.

SRERE, P. A. (1969). Citrate synthase. Methods in Enzymology, 13, 3-5.

STANFORD, S. C. (1990). Central adrenoreceptors in response and adaptation to stress. In D. J. Heal \& C. A. Marsden (Eds.), The pharmacology of noradrenaline in the central nervous system (pp. 379-422). Oxford: Oxford University Press.

Stockmeier, C. A., Martino, A. M., \& Kellar, K. J. (1985). A strong influence of serotonin axons on $\beta$-adrenergic receptors in rat brain. Science, 230, 323-325.

Sugrue, M. F. (1983). Some effects of chronic antidepressant treatments on rat brain monoaminergic systems. Journal of Neural Transmission, 57, 281-195.

Velazquez-Moctezuma, J., \& Ruiz, A. O. (1992). Neonatal treatment with clomipramine increased immobility in the forced swim test: An attribute of animal models of depression. Pharmacology, Biochemistry \& Behavior, 42, 737-739.

ViJaYakumar, M., \& METI, B. L. (1999). Alterations in the levels of monoamines in discrete brain regions of clomipramine-induced animal model of endogenous depression. Neurochemistry Research, 24, 345-349.

Vogel, G. W., Hagler, M., Hennessey, A., \& Richard, C. (1996) Dose-dependent decrements in adult male rat sexual behavior after neonatal clorimipramine treatment. Pharmacology, Biochemistry \& Behavior, 54, 605-609.

Vogel, G. W., Neill, D., Hagler, M., \& Kors, D. (1990). A new animal model of endogenous depression: A summary of present findings. Neuroscience \& Biobehavioral Reviews, 14, 85-91.

Vogel, G. W., Neill, D., Hagler, M., Kors, D., \& Hartley, D. (1990). Decreased intracranial self-stimulation in a new animal model of endogenous depression. Neuroscience \& Biobehavioral Reviews, 14, 65-68.

Vogel, G. W., Neill, D., Kors, D., \& Hagler, M. (1990). REM sleep abnormalities in a new animal model of endogenous depression. Neuroscience \& Biobehavioral Reviews, 14, 77-83.

Weiss, J. M., Goodman, P. A., Losito, B. G., Corrigan, S., Charry, J. M., \& BaILEY, W. H. (1981). Behavioral depression produced by an uncontrollable stressor: Relationship to norepinephrine, dopamine, and serotonin levels in various regions of rat brain. Brain Research, 3, 167-205.

White-Welkley, J. E., Bunnell, B. N., Mougey, E. H., Meyerhoff, J. L., \& Dishman, R. K. (1995). Treadmill exercise training and estradiol differentially modulate hypothalamic-pituitary-adrenal cortical responses to acute running and immobilization. Physiology \& Behavior, 57, 533-540.

YaVari, P., Vogel, G. W., \& Neill, D. B. (1993). Decreased raphe unit activity in a rat model of endogenous depression. Brain Research, 611, 31-36.

Yoo, H. S., Bunnell, B. N., Crabie, J. B., Kalish, L. R., \& Dishman, R. K. (2000). Failure of neonatal clomipramine treatment to alter forced swim immobility: Chronic treadmill or activity wheel running and imipramine. Physiology \& Behavior, 70, 407-411.

(Manuscript received July 26, 1999; revision accepted for publication May 8, 2000.) 